\title{
Convenient Community Service System Based on Integrated Service Platform
}

\author{
Wenjun Chang ${ }^{1, a^{*}}$, Gongfa $\mathrm{Li}^{1, \mathrm{~b}}$ and Wenlong $\mathrm{Hu}^{1, \mathrm{c}}$ \\ ${ }^{1}$ Wuhan University of Science and Technology, China \\ a1519738162@qq.com, bligongfa@wust.edu.cn, '942599328@qq.com,
}

Keyword: Modernization community; Network technology; Integrated services; Intelligent; Community security

\begin{abstract}
In order to manage, protect and make benefits to community, a community convenient service system based on information service platform has been put forward. The residents can be access to convenient information by this system, such as the latest notice of community, weather and traffic conditions and so on. In this system, residents can directly pay for electricity, water, and property costs, parking fees by the computer and phone, so that residents do not have a waste of time and energy to pay all kinds of fees. And residents can view their own health in the medical section of convenience system. Community convenience service system is network integrated service platforms which include travel, safety, health, diet and shopping and so on.
\end{abstract}

\section{Introduction}

Now, many community convenient service systems are used. For example, Community online platform for adapting to retirement. The design of the community health service system, MDA-based development and design for community E-services platform etc. From the existing service system, it can be seen most of the community public services are run independently at present. The existing platforms are development only for a small part of community service. The service system is not truly convenient. Among all the public service is not closely linked. The basic dates are used repeatedly and the quality is not high. Public service resources can not be shared between. In view of the above problems, we put forward the community convenience service system based on IOT network and multiple information exchange platform, the system can help residents to solve a lot of problems, I believe that in the near future the system will service all communities. The system can promote the development of community unity, friendship and mutual aid better [1-3]. Compared with the traditional management mode, the community service system is more intelligent, comprehensive and convenient, it promotes the development of smart city better.

\section{The Design and Function of the Community Service System}

To solve the problems of community services system. We put forward the community convenience service system based on IOT network and multiple information exchange platform. The community service system includes registration, entry; modify the information, community modified, news, management fees, medical record system, visitors, forums, several aspects [4]. In order to be clearer, system adopts the structure of tree branches, community services system is shown in Fig. 1. 


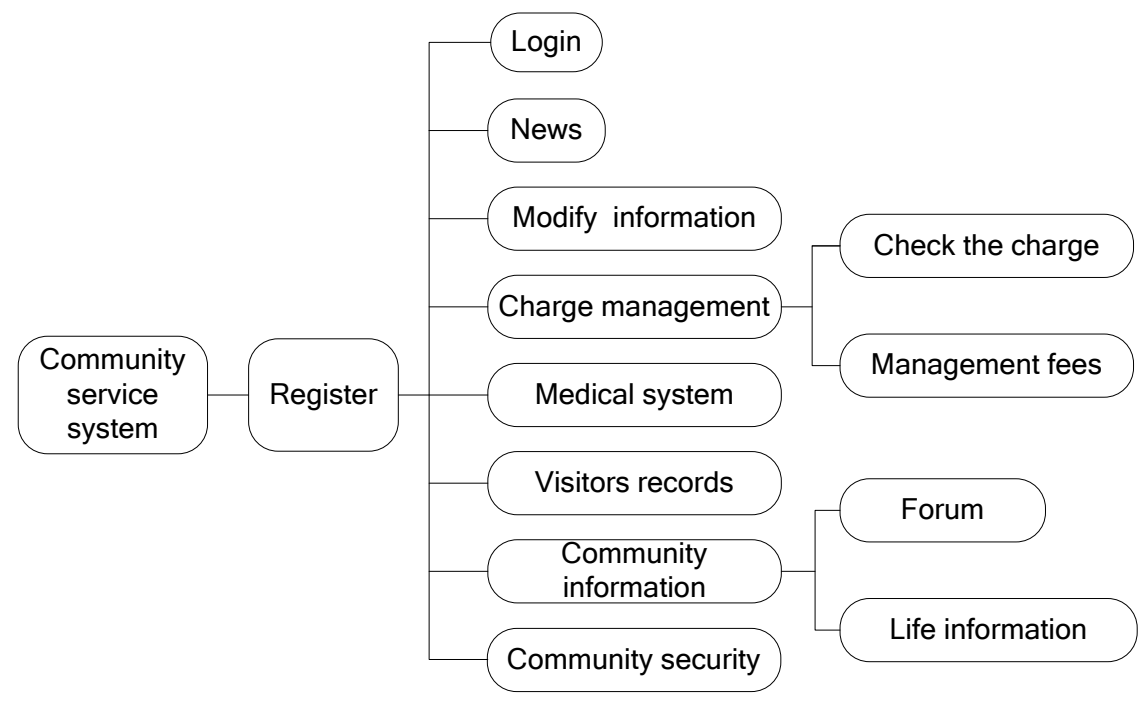

Figure 1. Community convenient service system

User Registration. The living environment has been changed by the Internet, now residents from more than 60 year old man, down to a few years old children will be online, so the system is simple and easy to operate [5]. The users first enter service system, register first, and then enter. Through the modification of information, all information of the community residents will be recorded and managed and achieve the integrity. The residential population may have been moved or moved in. The effectiveness of the system is that the information will not be missed and wrong, ensure the integrity of the information and manager update information. Registered users of the sequence diagram as shown in Fig. 2.

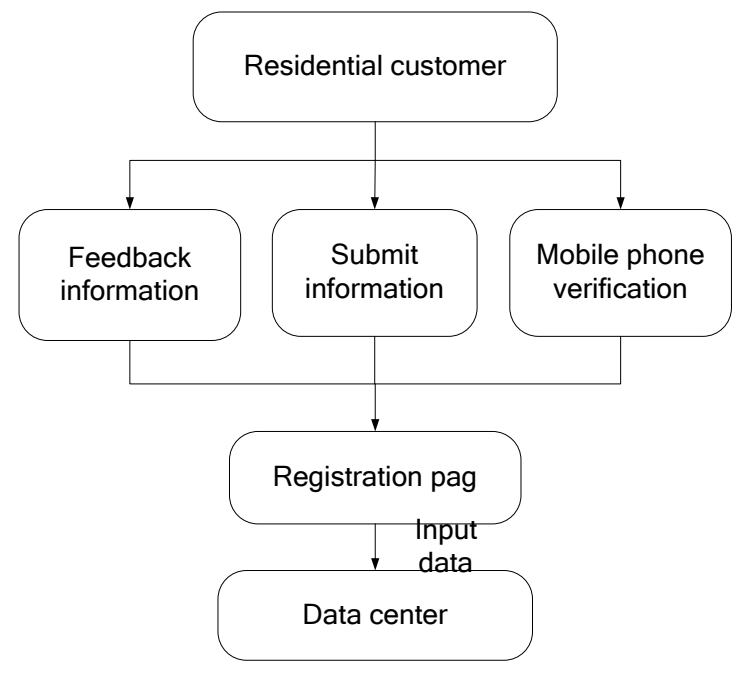

Figure 2. Registered users of the sequence diagram

News. News has been divided into three pieces, the first piece is foreign news, it mainly talk about the foreign events and headlines, the second block is the domestic news, the third block is community news of residents' lives, mainly about the good deeds and some honor of community residents. The effectiveness of this section is residents can browse the contents they favorite, propaganda the heroic deeds of community, this can let us know examples is in his side, it always reminds yourself that it starts from the side. It continuously improves residents' self-cultivation.

Community Security. For the safety of the community, the community all installed monitors, mounted on the door, the community every door, community shops and every road, in order to 
ensure the safety of the lives and property of residents. In order to strengthen community security measures, it provides video monitoring service for the community. Security forum of community service system will be able to display the situation of community once you entered[6].The effectiveness of this section is residential theft almost did not occur, the lives and property of residents get effective protection.

Charge Management. In the charging management section, community residents can solve all things related to the cost at home. In this system, residents can pay their own electricity, recharge amount, system supports a variety of ways treasure, net, and micro payment included. The effectiveness is residents can finish all lives' paid directly at home without busy running all over the places, it also facilitates the fees manager, to achieve a win-win. Charge management system is shown in Fig 3.

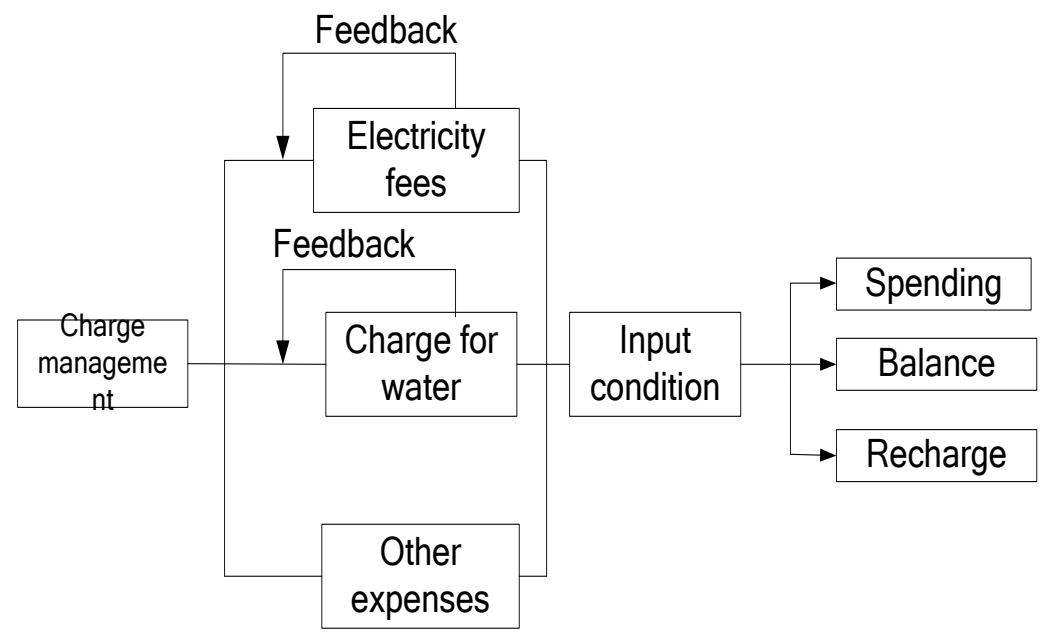

Figure 3. Charge management systems

Medical System. Medical system is mainly responsible for healthy lives of the residents, human beings are eat grain cereals, nobody does not get sick, so medical system plays an important role in the life of community residents, it is also the most "down to earth" part of our community service system. The community hospital will undergo a medical examination of the residents every year, and then put the data into the database, and finally establish the residents' health information. Community residents can view the historical changes of their health whenever and wherever possible. The most significant effect is that residents do not worry about the difficulty of going to hospital, their disease can also get timely treatment, health knowledge also helps a lot of, the health of people is getting better and better, sickness is less and death rate was decreased. Medical management system is shown in Fig. 4.

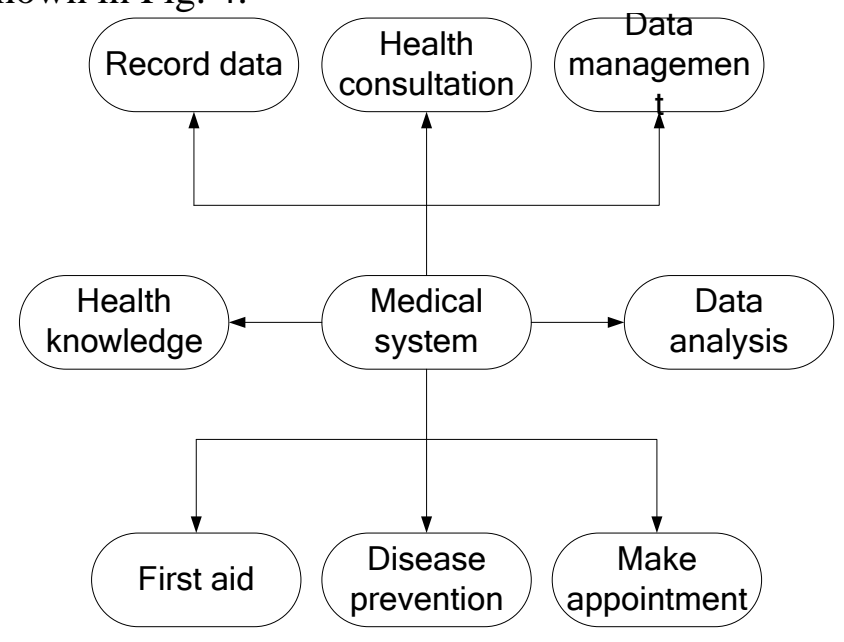

Figure 4. Medical management system 
Visitors Records. "Record visitors" system can record the number and the section which people get access to, you can clearly see which part does good which one is, so managers can make the good to do better, the bad place to be modified. "Record visitors" can also show children and adult men, women, the elder, in order to look at what kind of people visiting the most. The administrator can access those little logs into the system, and to do a survey to ask their opinions. Finally, the system becomes more perfect, more and more comprehensive, the satisfaction of the residents reached more than $85 \%$, which mainly due to the feedback function of recording system.

Community Information. Community information system is composed of communication and common information forum. In the forum, people can use the QQ, WeChat and some other communication software. Forum for the exchange of benefits are residents feeling better. Finally, the community has become a harmonious family [7]. Common information is composed of group purchase information services, business services, community life service information. Community residents can see on the name of the product, the original price, preferential price and sales volume of group purchase, product pictures and other information in the group purchase information [8-9]. A lot of money and time can be save for the residents in the group purchase of information service. Community group purchase service as shown in Fig. 5.

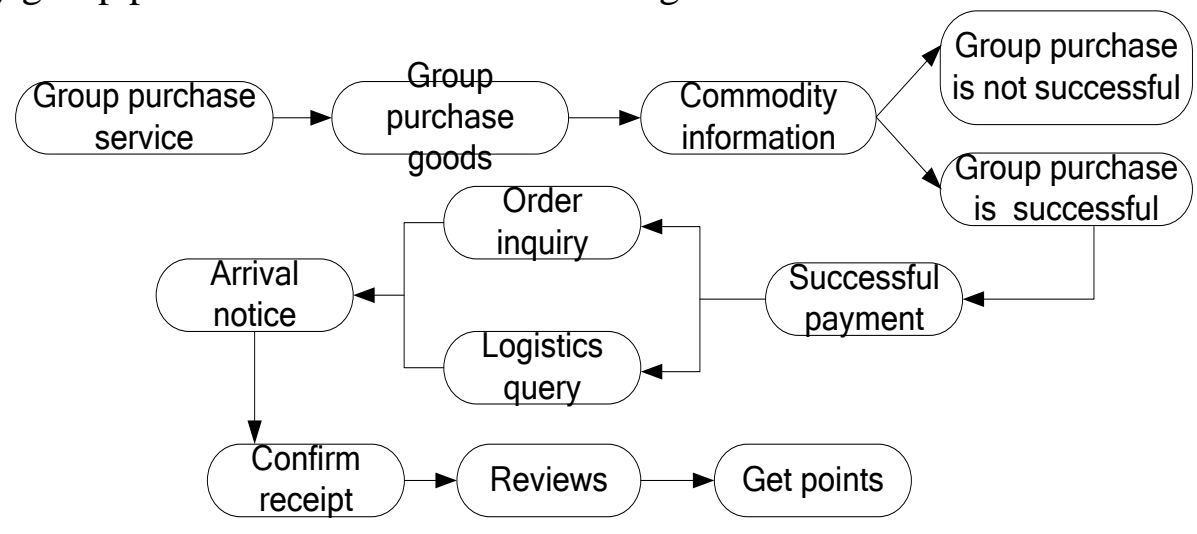

Figure 5. Community group purchase service

Community service is the main evaluation property repair, property notice, property and activities of community residents [10]. In the life of the service system, the residents can see the traffic information and weather information.

\section{The Key Technology and Implementation Effects of the Community Service System}

The key technology in the application of the service system is that the government internal office network and Internet network advantage are relied on. The network, intelligence and information are set as a whole. The computer technology, network technology, communication technology, multimedia technology and 3S (GIS, GPS, RS) technology are used, three level interoperability management platform is constructed In order to achieve the integration and sharing of information collection, processing, enhance the level of modern management and community information service ability, The ultimate goal is to realize office automation, interactive, network management and humanized service.

\section{Conclusion}

The community service system based on Networking and information exchange platform provide a convenient, efficient business services and life services for users, but also provide convenience for the payment of fees and checking. In terms of travel advice, it saves a lot of time and troubles for residents. The community services system includes the basic necessities of life, health, security and other services. The information for residents can be shared and avoid recorded repeatedly. 
Community has brought unexpected results after the introduction of community service system. People get along well with the other and the lives become better. Safety has been improved. In the next few years, the design of the system based on the platform of Android/ios will provide a more efficient, fast and convenient mobile Home Furnishing life for the residents.

\section{Reference}

[1] X.M Wu: On construction of intelligent residential district. Shanxi Architecture, Vol. 30(2004) No.18, p.29-30

[2] L.C Gong, P Xue: Design and implementation of digital community information management and service system. Geomatics Technology and Equipment, Vol. 10(2008) No.1, p.16-18

[3] L Sun: Design and application of intelligent public service broadcasting based on GIS. Video Engineering, Vol. 38(2014) No.14, p.65-68

[4] X Wu, T.Y Li: Study on Planning Framework of Convenience Service System for Village and Town Communities. Journal of Urban and Regional Planning, Vol. 7(2015) No.2, p.100-111

[5] J Cai, D.C Qiu and Z.Y Zhao, et al: A Research of the changes in residential environment in new rural communities_ A case study of tianzi village of zhongxian county. Journal of Southwest University, Vol. 35(2013) No.10, p.117-124

[6] J.M Zhang, X.M Wu: The design of digital community monitoring system. Control \& Automation, Vol. 25(2009) No.3, p.12-14

[7] S.S Zhu, Y.Q Zhang: Study on the design of the elderly Leisure City community social service retirement. Packaging Engineering, Vol. 36(2015) No.12, p.5-9

[8] L.M Wang, Y.Y Han and T Lei: The design of community service system. Microcomputer \& its Applications, Vol. 32(2013) No.16, p.11-13

[9] F.M Ma, G Wang: Method for commodity recommendation based on user community. Computer and Digital Engineering, Vol. 41(2013) No.8, p.1354-1356

[10]L.X Zhu Ge, N.X Liu: Key technologies of "One-Window" community affairs acceptance and process services system. Computer Systems \& Applications, Vol. 24 (2015) No.1, p.74-78. 